\title{
Classification and Processing of Joint Inventory Information on Maintenance Equipment for Military Training Vehicles Based on System Dynamics
}

\author{
Jianyong Guo ${ }^{1,2^{*}}$, Shaoqi Zhou ${ }^{1}$, Yuantao Zhang ${ }^{3}$, Wenqiang Wang ${ }^{1}$, Shuai Huang ${ }^{1}$, Min Lv $^{4}$ \\ ${ }^{1}$ Department of POL, Army Logistical University of PLA, Chongqing 401331, China \\ 232150 troops of PLA, Xinxiang 453002, China \\ ${ }^{3}$ Logistics University of PAP, Tianjin 300309, China \\ ${ }^{4}$ Henan University Minsheng College, Kaifeng 475001, China
}

Corresponding Author Email: 405597859@qq.com

https://doi.org/10.18280/jesa.520114

Received: 10 November 2018

Accepted: 15 January 2019

\section{Keywords:}

joint inventory, vehicle maintenance equipment, military training vehicles (MTVs), system dynamics, information classification

\begin{abstract}
The military training vehicles (MTVs) should be maintained frequently. The high frequency, coupled with the various maintenance equipment, calls for a strong information processing capability. Therefore, this paper designs a classification and processing method for the joint inventory information on maintenance equipment, aiming to improve the production, supply and maintenance of the MTV maintenance supply chain. Inspired by the system dynamics, the author set up a dynamic simulation model for the joint inventory management of MTV maintenance equipment, and constructed an index called the priority of training vehicle equipment supply (PTVES). Then, the dynamic performance of the system was investigated under different supply support tasks for maintenance equipment. The research provides a reference for the joint inventory management strategy of MTV maintenance supply chains.
\end{abstract}

\section{INTRODUCTION}

Vehicle maintenance equipment is the material basis for vehicle maintenance work, and also an important guarantee for military vehicles to be equipped into systems and form combat effectiveness. The supply of vehicle maintenance equipment has always been a difficult issue in the field of vehicle maintenance. In order to solve the problems of non-demanded supply, non-usable storage, fragmentation pattern, and waste of resources in the supply of military materials, many scholars inside and outside the military have done a lot of researches: Li [1] compared the changes in the inventory cost of each entity in the supply chain before and after implementing the vendor inventory management, and demonstrated the feasibility of vendor inventory management during the operation of military maintenance equipment supply chain; Wang [2] used the digital modalization method to optimize the combination unit of vehicle tactical reserve equipment; He [3] proposed four modes of inventory management with the purpose to improve the efficiency of vehicle supply chain management; Through analysis for the virtual warehouse function, architecture and operation platform of military vehicle maintenance equipment, Guo [4] designed the network topology, creatively proposed the normal-integrated operation mode and developed the operation process; Ge [5], aiming at minimizing the inventory management cost, proposed the twolevel inventory model based on the virtual centre, and provided the inventory control strategy for the non-repairable spare parts.

The above theories have played a certain guiding role in solving the problems in the supply of Military vehicle maintenance equipment, but most of them are limited to the static quantitative research for specific types of vehicles. The supply support task of military vehicle maintenance equipment is a complex dynamic process involving thousands of equipment information processing, sharing and exchange. Due to the high frequency of maintenance equipment flow and demand, multiple vehicle transportation information needs to be processed within a unit time. Therefore, it is an urgent task in the supply support activities of military vehicle maintenance equipment on how to determine the priority of the vehicle maintenance equipment supply support task from the perspective of system dynamics, and then analyse the longterm dynamic characteristics of the maintenance equipment supply chain management.

This paper takes the jointly managed inventory (IMI) of MTVs' vehicle maintenance equipment as the research object, and constructs a System Dynamics model to analyse the supply chain information sharing and equipment flow under various supply support tasks. Then, in the case of insufficient equipment support data, quantitative analysis was performed about the key parameters in the system dynamics model. This shall provide a reference for the JMI of China's military vehicle maintenance equipment.

\section{JOINTLY MANAGED INVENTORY OF MTVS' MAINTENANCE EQUIPMENT}

\subsection{JMI concept}

Jointly Managed Inventory (JMI) is a management model developed on the basis of Vendor Managed Inventory (VMI) [6]. The JMI model means that both vendors and users participate in and formulate inventory plans, and the supply and demand sides share demand information in the supply chain, which reflects the idea of integrated supply chain management. This model effectively controls the inventory 
risk in the supply chain, better adapts to the requirements of market changes, and enhances the integrity and coordination of the entire supply chain [7-10], as shown in Figure 1.

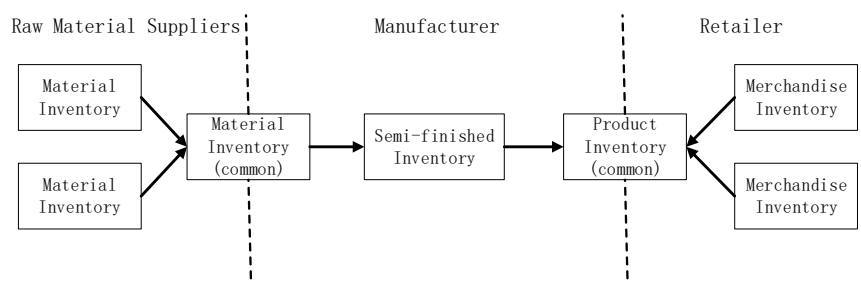

Figure 1. Jointly managed inventory model

\subsection{JMI process for MTVs' maintenance equipment}

The joint inventory of MTVs' maintenance equipment refers to the supply chain of military vehicle maintenance equipment established on the basis of JMI theory to meet the supply requirements of maintenance equipment during the military training process. It applies the integrated management ideas to solve the demand amplification caused by the mutual independent operation of the traditional equipment supply chain system, and can fully utilize the local vehicle maintenance equipment resources, so as to improve the information sharing level in the supply support activities and reduce the cost of supply support.

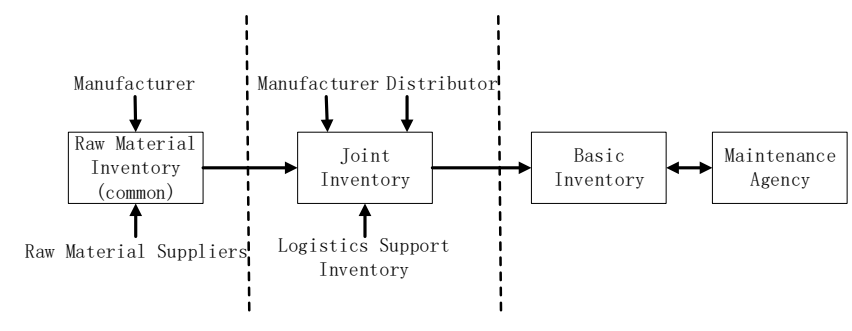

Figure 2. Joint inventory supply chain model of military vehicle equipment

It can be seen from Figure 2 that the joint inventory supply chain system of MTVs' maintenance equipment not only has the vertical combination from raw material inventory to grassroots military vehicle inventory, but also the horizontal joint of military vehicle warehouse and local vehicle warehouse. The process can be described as follows:

(1) The joint inventory supply chain model is established on the basis of the two-level maintenance concept of "front replacement, rear repair" for maintenance equipment, emphasizing on the supply support activities of the joint inventory to the grassroots units. The main participants include the maintenance equipment manufacturer, distributor warehouses, warehouse of military joint guarantee department, grassroots warehouses, and maintenance agency of military vehicle maintenance equipment.

(2) In the supply chain system, the maintenance equipment manufacturer, the warehouse of military joint guarantee department, and the distributor warehouse form a joint warehouse of vehicle equipment, which can be a new or rented warehouse near the grassroots unit, a third-party logistics, or network virtual warehouse. The model considers the time delay of the vehicle equipment in the process of production, transportation, storage and maintenance, but not the replacement time of the ex-warehousing equipment.

(3) The joint inventory supply chain of vehicle equipment is driven by the demand for vehicle equipment of grassroots units. Assuming that alternate maintenance is made for all damaged components of the military vehicle, the vehicle with damaged components calls for the maintenance, and the reserve of the grassroots inventory is reduced; then, the defective components are all sent to the maintenance agency, and returned to the grassroot warehouse after repairs, but the unrepairable are scrapped. The just-in-time procurement strategy is used for raw materials, to meet the raw material demand in time and reduce the inventory; for the joint warehouse, the vehicle maintenance equipment warehouse, and the semi-finished warehouse of vehicle equipment etc., the fixed-supplier ordering strategy is adopted, which is conducive to reducing the inventory level and the stockout cost.

(4) The model sets up the upstream and downstream information centres. The upstream is centred on the demand information of the joint warehouse, and the raw material ordering, and the production of semi-finished products and finished products are all processed by the upstream information centre; the downstream is centred on the demand information of military warehouse, and the demands of grassroots units, the ex-warehousing rate of equipment from joint warehouse, and the priority information of vehicle equipment supply support are all processed by the downstream information centre.

\section{JOINT INVENTORY SYSTEM DYNAMICS SIMULATION MODEL OF MTVS' MAINTENANCE EQUIPMENT}

System Dynamics [12] is an interrelated complex system that quantitatively describes the dynamic characteristics of simulation systems using simulation language, especially for higher-order, nonlinear, multi-feedback loops (Feedback Loop) complex system issues.

For the joint inventory of vehicle equipment, the method of system dynamics can be adopted by combining the qualitative and quantitative research both to grasp the dynamic characteristics of equipment supply, and observe the influence of system parameter changes on the whole system. It plays an important role in grasping the logical relationship and variation trend of each feedback loop in the supply chain system.

Through the analysis for the causal relationship of various factors in the system, this paper uses Vensim PLE [13] software to draw the causal graph and stock-flow graph of the joint supply chain system for MTVs' maintenance equipment, and establish the equations of each variable to conduct the model reality testing and the unit test. This shall provide reference for formulating the related supply strategy through simulation of the system dynamic characteristics.

\subsection{The causality of the joint inventory system for MTVs' maintenance equipment}

According to the joint management process description of MTVs' maintenance equipment, the causal relationship between the variables in the equipment supply chain was drawn, as shown in Figure 3. 


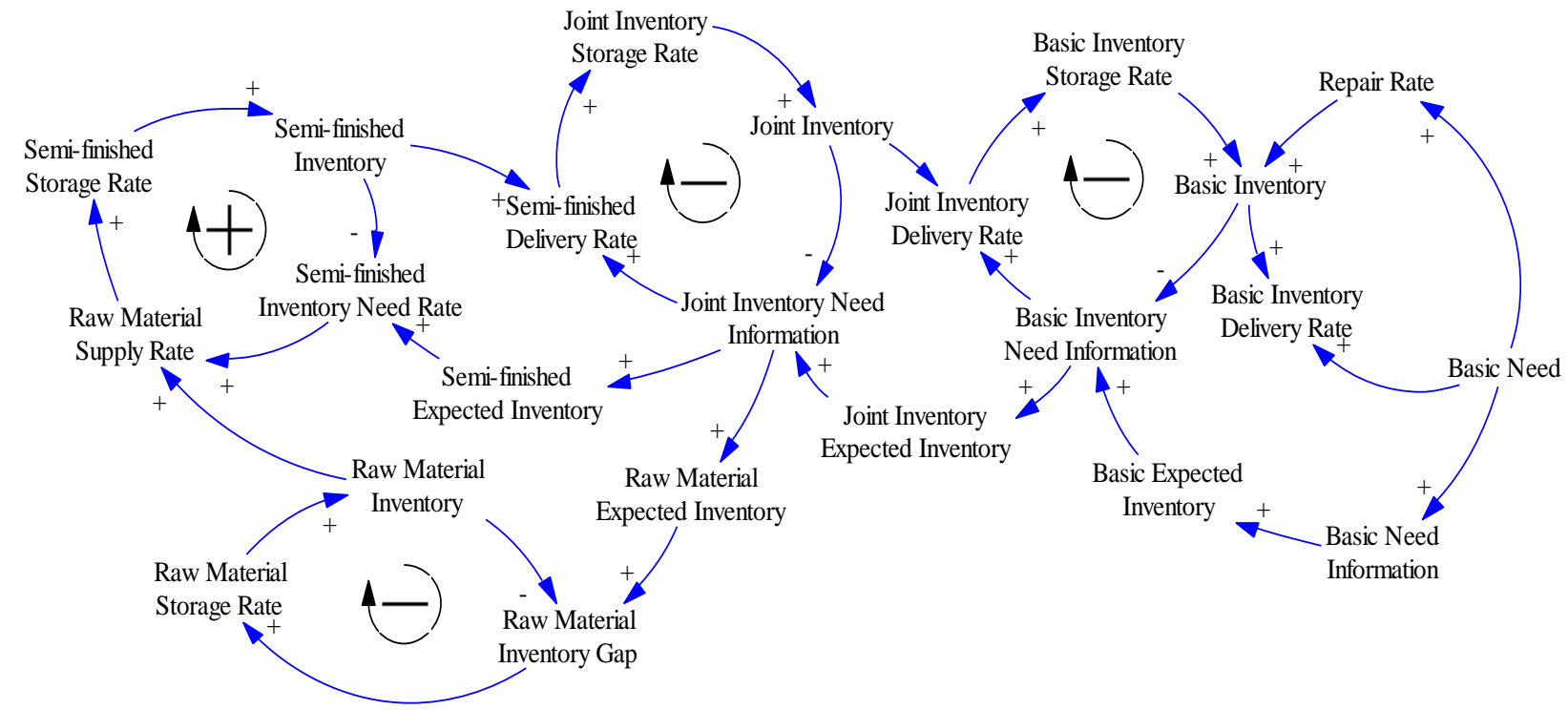

Figure 3. Casual graph of joint warehouse for military vehicle equipment

It can be seen from Figure 3 that the causal graph of the joint inventory system consists of two parts: information flow and physical flow. The vehicle equipment of finished and semifinished products, and inventory level of raw materials is determined by in- and ex-warehousing rate of goods, e.g., the inventory of the military warehouse is affected by the repair rate of damaged vehicle equipment, the receiving rate and the delivery rate of the military warehouse; the delivery rate is determined by the current inventory level and demand information, e.g., the delivery rate of joint warehouse is affected by the joint warehouse inventory and military warehouse demand information. A lossy cycle of production, storage, supply and maintenance is formed for the vehicle equipment. The driving source of the whole system operation is the demand for vehicle equipment caused by the equipment failure.

\subsection{Joint inventory system dynamics model of military vehicle materials}

Vensim is a visual modelling tool that conceptualizes and documents system dynamics models, and makes model simulation, analysis, and optimization. It provides a simple and flexible way to model the causal graph and stock-flow graphs. In the flow graph, there are some flow levels (accumulation of flow within the system), flow rate (flow in/out per unit time), and auxiliary variables [12]; the mathematical expression of each variable is given in the DYNAMO language, and the state equation is established. Figure 4 shows the flow chart of the model in the procurement, production, supply and maintenance of raw materials for military vehicle equipment.

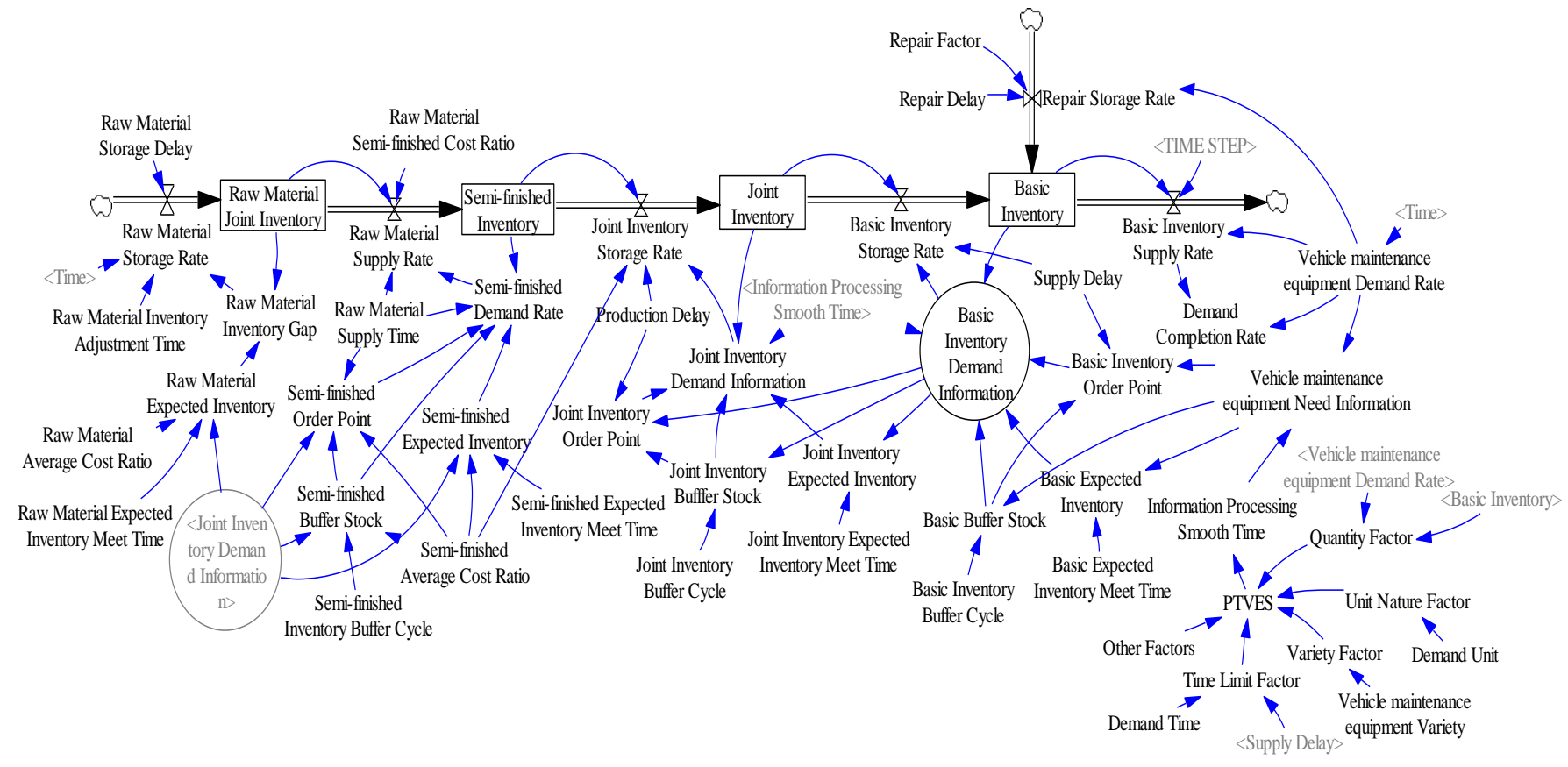

Figure 4. Joint inventory dynamic model of military vehicle equipment 
Considering the influence of production time, transportation time, maintenance time and other factors on raw materials, the vehicle equipment of semi-finished products and finished products during the flowing process in warehouses at all levels, the variables are added to the model, including the production delay, manufacturing time of raw materials, travelling time of vehicle equipment, and maintenance delay; because a certain time delay is generated in the processing and sharing process of vehicle material information, the smoothing time is added; in view of the difference in the priority of different types and quantities of vehicle equipment supply supports, the PTVES priority table function is added. In order to ensure the completion rate of equipment demand, the inventory management method of fixed-supplier order is used for the inventory of vehicle equipment, joint inventory, and semifinished products inventory; periodic replenishment is taken for the inventory of raw materials, in consideration for the purchasing cost of raw materials. The main equations of the system are as follows:

Vehicle equipment inventory of military warehouse = INTEG (warehousing rate of vehicle equipment for repair + receiving rate of vehicle equipment from military warehouse - ex-warehouse rate of vehicle equipment, 50)

Vehicle equipment demand information of military warehouse $=$ IF THEN ELSE (vehicle equipment inventory of military warehouse $<=$ military warehouse order point, (expected inventory- buffer inventory of military warehouse)/information processing smoothing time, 0)

Vehicle equipment receiving rate of military warehouse $=$ DELAY1 (MIN (vehicle equipment warehouse of joint warehouse/travelling time of vehicle equipment, vehicle equipment demand information), travelling time of vehicle equipment)

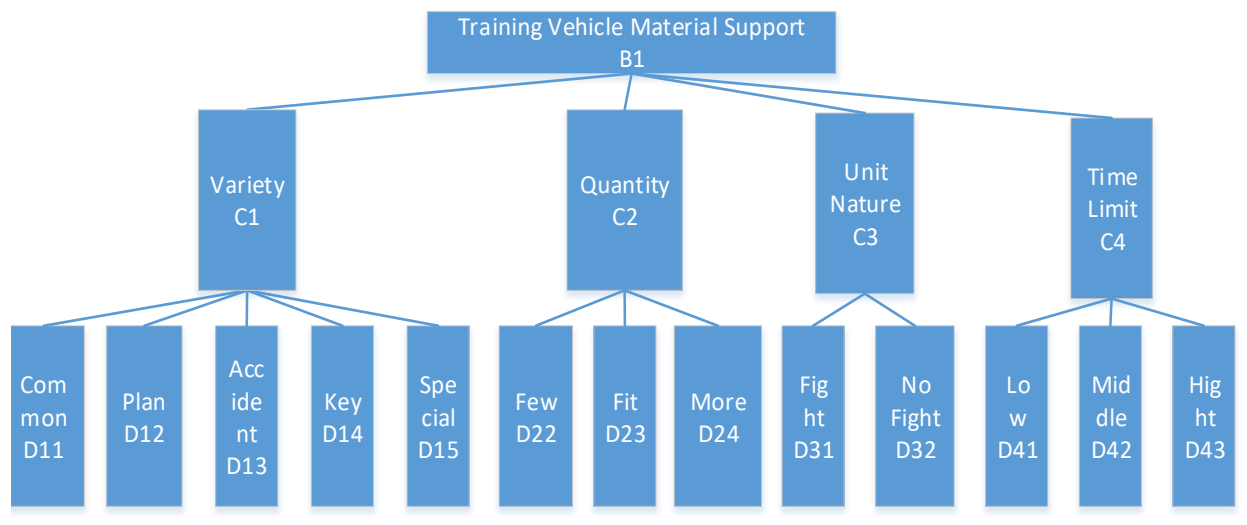

Figure 5. PTVES hierarchical model

Types of vehicle equipment: in terms of usage, the vehicle equipment can be divided into five categories: special vehicle equipment, key vehicle equipment, accident equipment, planned equipment and common vehicle equipment.

Number of vehicles: In this model, it's considered to be higher when the demand for vehicle equipment is not less than $70 \%$ of the military warehouse inventory; to be moderate when it's between $30 \%$ and $70 \%$; to be lower when it's less than $30 \%$. In actual applications, the standard quantity demanded should be comprehensively defined in terms of the different factors such as the production capacity, maintenance capacity, and transportation capacity etc.

Nature of unit: According to the nature, it can be divided into combat units and non-combat units. Combat units refer to
Vehicle equipment inventory of joint warehouse $=$ INTEG (warehousing rate of vehicle equipment in joint warehousevehicle equipment receiving rate of military warehouse, 100)

Joint warehouse demand information = IF THEN ELSE (Vehicle equipment inventory in joint warehouse $<=$ order point of joint warehouse, (joint warehouse expected inventory - joint warehouse buffer inventory) / information processing smoothing time, 0)

Semi-finished product inventory of vehicle equipment $=$ INTEG (raw material supply rate - warehousing rate of vehicle equipment in joint warehouse, 300)

Joint inventory of raw material = INTEG (warehousing rate of raw material - raw material supply rate, 600)

Raw material warehousing rate $=$ IF THEN ELSE (MODULO (Time, adjustment time of raw material inventory) $=0$, difference of raw material inventory /raw material storage delay, 0)

\subsection{Determination of PTVES table functions}

PTVES (Priority of Training Vehicle Equipment Supply) table function is determined according to the characteristics of MTVs' maintenance equipment such as strong planning, stable demand and long duration of the military training. Together with the relevant factors, the AHP method was used to establish the PTVES hierarchical model (Figure 5), and the weights of different support tasks were calculated. Based on this, the priority level of the vehicle equipment support task was determined by the information system, and then the joint warehouse information centre determines the response time of this supply support task according to the priority. 


$$
\begin{aligned}
& {\left[D_{2}-C_{2}\right]=\left[\begin{array}{ccc}
1 & 3 & 5 \\
1 / 3 & 1 & 2 \\
1 / 5 & 1 / 2 & 1
\end{array}\right]} \\
& {\left[D_{3}-C_{3}\right]=\left[\begin{array}{ll}
0.7 & 0.3
\end{array}\right]} \\
& {\left[D_{4}-C_{4}\right]=\left[\begin{array}{ccc}
1 & 3 & 5 \\
1 / 3 & 1 & 2 \\
1 / 5 & 1 / 2 & 1
\end{array}\right]} \\
& {\left[\mathrm{C}-\mathrm{B}_{1}\right]=\left[\begin{array}{llll}
0.3 & 0.3 & 0.2 & 0.2
\end{array}\right]}
\end{aligned}
$$

After the model calculation and the consistency test completed, the weights of the D layer to the $\mathrm{C}$ layer, the $\mathrm{C}$ layer and the B layer were obtained.

$[D 1-C 1]=(0.4439,0.2929,0.1291,0.0815,0.0525)$

$[\mathrm{D} 2-\mathrm{C} 2]=(0.6483,0.2297,0.1220)$

$[\mathrm{D} 3-\mathrm{C} 3]=(0.7,0.3)$

$[\mathrm{D} 4-\mathrm{C} 4]=(0.6483,0.2297,0.1220)$

$[\mathrm{C}-\mathrm{B} 1]=(0.3,0.3,0.2,0.2)$

Then, the weight of $\mathrm{D}$ layer to $\mathrm{B}$ layer is:

$[\mathrm{D} 1-\mathrm{B}]=(0.1332,0.0879,0.0387,0.0245,0.0158)$

$[D 2-B]=(0.1945,0.0689,0.0366)$

$[\mathrm{D} 3-\mathrm{B}]=(0.14,0.06)$

$[\mathrm{D} 4-\mathrm{B}]=(0.1297,0.0459,0.0244)$

Using Python programming, add up the weight ratios of each individual respectively and arrange the values from large to small.

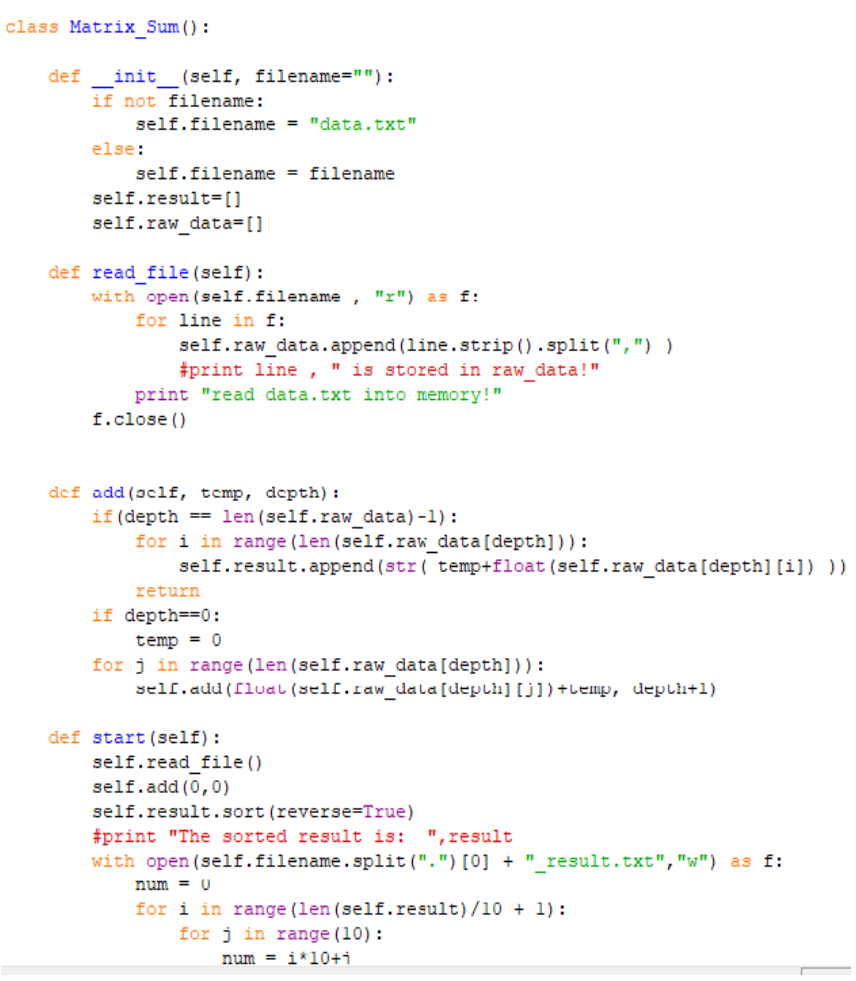

Figure 6. Weight calculation using the Python program

The weight value outputs are:

$0.5974,0.5521,0.5174,0.5136,0.5029,0.4921$,

$0.4887,0.48,0.4721,0.4718,0.4683,0.4468$,

$0.4395,0.4336,0.4265,0.4229,0.4191,0.4121$,

$0.4087,0.4049,0.4,0.3976,0.3962,0.3942$,

$0.3918,0.3883,0.388,0.3834,0.3773,0.3747$,

$0.3668,0.3664,0.3631,0.3595,0.3557,0.3544$,

$0.3465,0.345,0.3427,0.3391,0.3342,0.3308$,

$0.3249,0.3221,0.3212,0.3176,0.3162,0.3142$,

$0.3104,0.308,0.3034,0.2973,0.2947,0.2935$,

$0.2889,0.2865,0.2831,0.2793,0.2757,0.2744$,

$0.272,0.2706,0.265,0.2627,0.2612,0.2578$,
$0.2542,0.2508,0.2491,0.247,0.2421,0.2412$, $0.2397,0.2383,0.2304,0.2255,0.2168,0.2135$, $0.2089,0.1993,0.192,0.1906,0.1812,0.1778$,

$0.1691,0.167,0.1597,0.1583,0.1455,0.1368$

Assuming that the joint warehouse information centre can process 9 vehicle supply support task information per unit time, PTVES can be classified into 11 levels.

PTVES table function is expressed as $=[(0,1)-(0.7,3)],(0,3)$, $(0.1906,2.8),(0.2397,2.6),(0.2627,2.4),(0.2889,2.2)$, $(0.3176,2),(0.3465,1.8),(0.3834,1.6),(0.4087,1.4),(0.4718$, $1.2),(0.7,1)$, as shown in Figure 7.

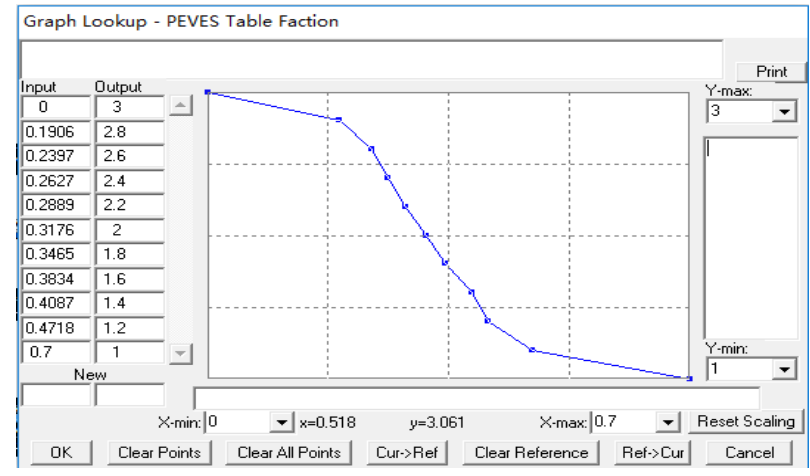

Figure 7. PTVES table functions

The parameters affecting PTVES are shown as:

Time limit factor: A table function that determines the output value based on the ratio of supply time to demand time.

Vehicle equipment type factor: a table function that determines the output value according to the type of vehicle equipment required.

Units of demand: it's divided into combat units and noncombat units, numbered 0 and 1 , respectively.

Other factors: it refers to the factors affecting the PTVES priority, such as climate, road network rate, and administrative orders, in addition to the four major factors. When there is no external influence, this variable is 0 .

According to the weight calculation, the values of several factor table functions are as follows:

Table function of time limit factor $=[(0,0)-(1,0.1297)],(0$, $0),(0.3,0.0244),(0.7,0.0453),(1,0.1297)$,

Table function of vehicle equipment quantity factor $=[(0,0)$ $(10,0.1945)],(0.3,0.0366),(0.7,0.0689),(1,0.1945),(10$, $0.1945)$,

Table function of vehicle equipment type factor $=[(0$, $0.0158)-(4,0.1332)],(1,0.0879),(2,0.0387),(3,0.0245),(4$, $0.0158)$,

Table function of unit nature factor $=[(0,0.06)-(1,0.14)],(0$, $0.14),(1,0.06)$ 。

\section{APPLICATION OF JOINT INVENTORY SYSTEM DYNAMICS MODEL FOR MTVS' MAINTENANCE EQUIPMENT}

\subsection{Determination of parameters related to PTVES table function}

This paper selects the annual vehicle maintenance equipment demand for two different natures of units (combat units and non-combat units) as the research object. Table 1 lists the relevant parameters of the vehicle equipment types obtained in the survey: 
Table 1. Types of research objects

\begin{tabular}{|c|c|c|c|}
\hline $\begin{array}{c}\text { Demand } \\
\text { unit }\end{array}$ & $\begin{array}{c}\text { Vehicle } \\
\text { model }\end{array}$ & $\begin{array}{c}\text { Demanded } \\
\text { vehicle } \\
\text { equipment }\end{array}$ & $\begin{array}{c}\text { Types of } \\
\text { vehicle } \\
\text { equipment }\end{array}$ \\
\hline $\begin{array}{c}\text { Combat } \\
\text { unit }\end{array}$ & $\begin{array}{c}\text { ZSL92 } \\
\text { Infantry } \\
\text { Fighting } \\
\text { vehicle }\end{array}$ & $\begin{array}{c}\text { Bullet proof } \\
\text { tyre }\end{array}$ & $\begin{array}{c}\text { Special vehicle } \\
\text { equipment }\end{array}$ \\
\hline $\begin{array}{c}\text { Non- } \\
\text { combat } \\
\text { unit }\end{array}$ & $\begin{array}{c}\text { CA1121 } \\
\text { Carrier } \\
\text { vehicle }\end{array}$ & $\begin{array}{c}\text { Rearview } \\
\text { mirror }\end{array}$ & $\begin{array}{c}\text { Common } \\
\text { vehicle } \\
\text { equipment }\end{array}$ \\
\hline
\end{tabular}

The monthly demand for vehicle equipment during the year is shown in Table 2.

Table 2. Annual demand data of vehicle equipment

\begin{tabular}{|c|c|c|}
\hline Month & Bullet proof tyre & Rearview mirror \\
\hline 1 & 64 & 86 \\
\hline 2 & 75 & 91 \\
\hline 3 & 78 & 97 \\
\hline 4 & 53 & 153 \\
5 & 61 & 76 \\
6 & 58 & 63 \\
7 & 63 & 76 \\
8 & 76 & 87 \\
9 & 69 & 91 \\
10 & 59 & 94 \\
11 & 45 & 99 \\
12 & 43 & 88 \\
\hline
\end{tabular}

Demand factor and table function of ZSL92 bulletproof tire and CA1121 rearview mirror are as follows:

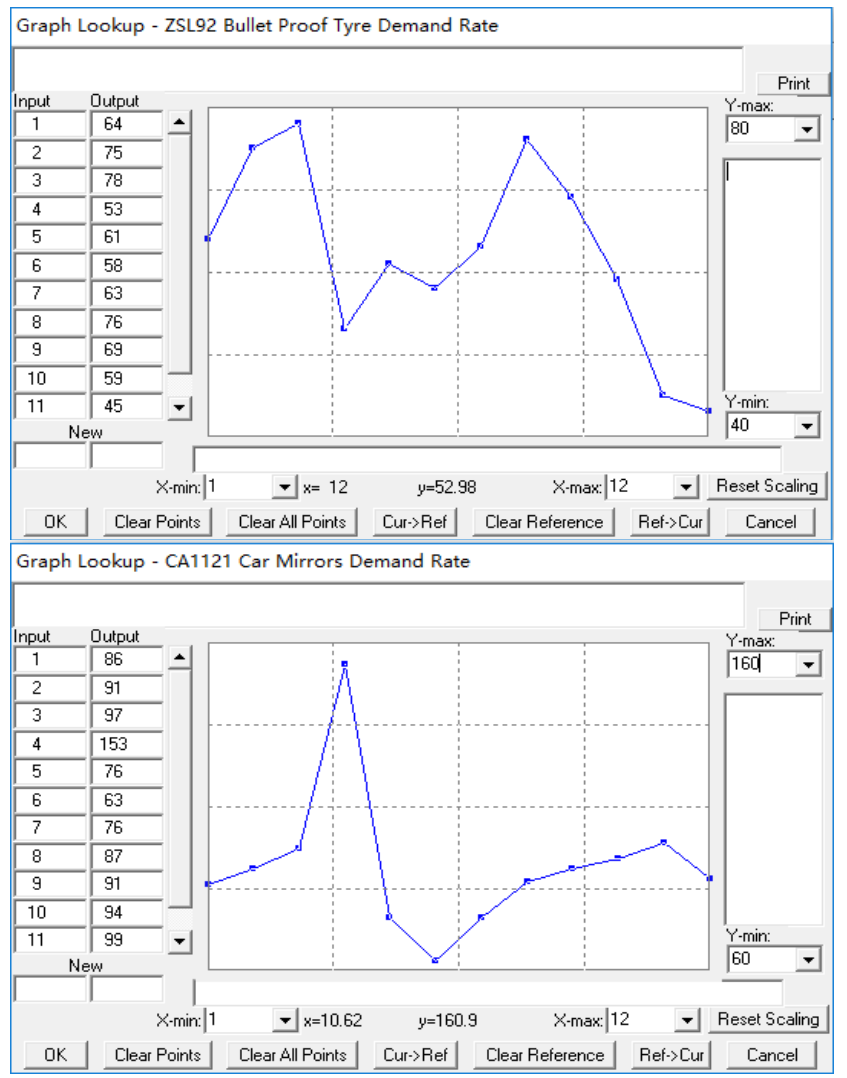

Figure 8. Demand factor table functions of two types of vehicle equipment
The two table functions are shown as:

ZSL92bullet proof tyre $=[(1,40)-(12,80)],(1,64),(2,75)$, $(3,78),(4,53),(5,61),(6,58),(7,63),(8,76),(9,69),(10$, $59),(11,45),(12,43)$.

CA1121 rearview mirror $=[(1,60)-(12,160)],(1,86),(2$, $91),(3,97),(4,153),(5,76),(6,63),(7,76),(8,87),(9,91)$, $(10,94),(11,99),(12,88)$.

Table 3. The relevant parameter values affecting the PTVES of two types of vehicle equipment

\begin{tabular}{|c|c|c|c|}
\hline Demand unit & $\begin{array}{c}\text { Unit } \\
\text { parameter }\end{array}$ & $\begin{array}{c}\text { Other } \\
\text { factors }\end{array}$ & $\begin{array}{c}\text { Types of vehicle } \\
\text { equipment } \\
\text { required }\end{array}$ \\
\hline Combat unit & 0 & 0 & 0 \\
\hline Non-combat unit & 1 & 0 & 4 \\
\hline
\end{tabular}

The time limit factor and the equipment quantity factor are changing dynamically. The time limit factor is determined by the ratio of the supply support time to the demand time limit when the vehicle equipment demand is generated; the vehicle equipment quantity factor is determined by the ratio of the vehicle equipment demanded quantity and the corresponding inventory of vehicle equipment in the grassroots military warehouse at that time.

\subsection{Simulation of joint inventory system dynamics model}

With the parameters in the system dynamic model of the joint warehouse unchanged, the demand factor table function of the ZSL92 bulletproof tire and CA1121 rearview mirror were set as the demand rate of vehicle equipment. The comparison results are as follows:
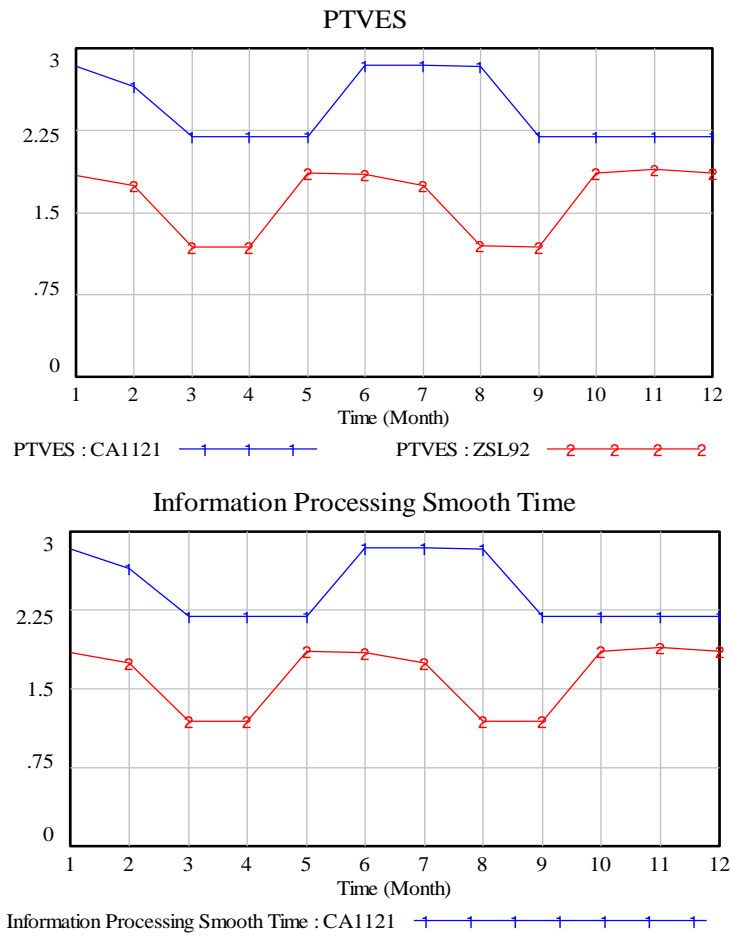

Information Processing Smooth Time : ZSL92 \begin{tabular}{llllllll}
\hline & 2 & 2 & 2 & 2 & 2 & 2
\end{tabular}

Figure 9. PTVES priority and information processing time

It's specified in this paper that that the lower the value of the PTVES table function, the higher the priority. Figure 9 shows that the priority value of the bulletproof tire is significantly higher than that of the rearview mirror (average 
values:1.65, 2.44, respectively); the higher the PTVES priority, the shorter the information processing smoothing time.

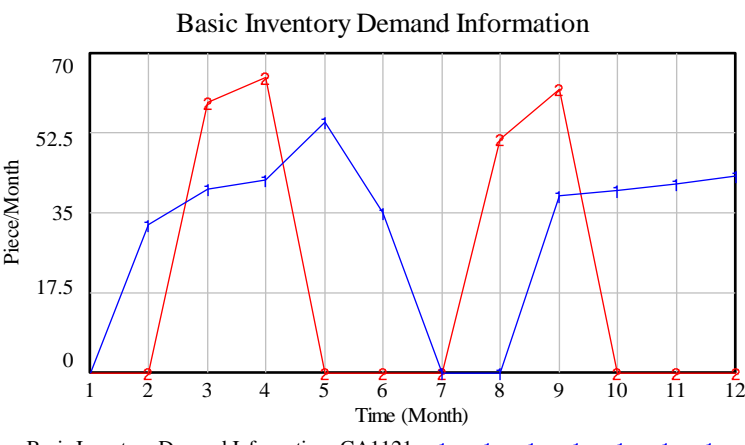

Basic Inventory Demand Information : CA1121 Basic Inventory Demand Information : ZSL92

Joint Inventory Demand Information

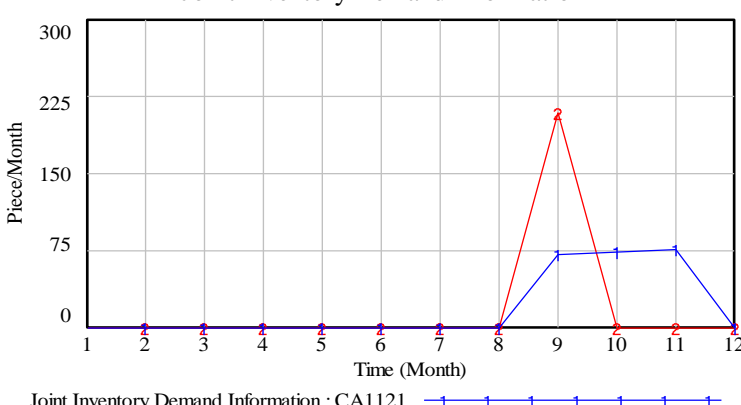

Joint Inventory Demand Information : ZSL92

Figure 10. Vehicle equipment demand information

Figure 10 shows that the average joint warehouse demand information of the CA1121 rearview mirror and the ZSL92 bulletproof tire was 18.27 and 17.27 , respectively, and the average demand information of the military warehouse was 30.64 and 19.68 respectively. From the curve change, the PTVES of ZSL92 bulletproof tire has higher priority, its demand curve changes sensitively, and the demand duration is shorter; the PTVES of CA1121 rearview mirror has lower priority, and its demand curve changes more gently, but the demand lasts longer.
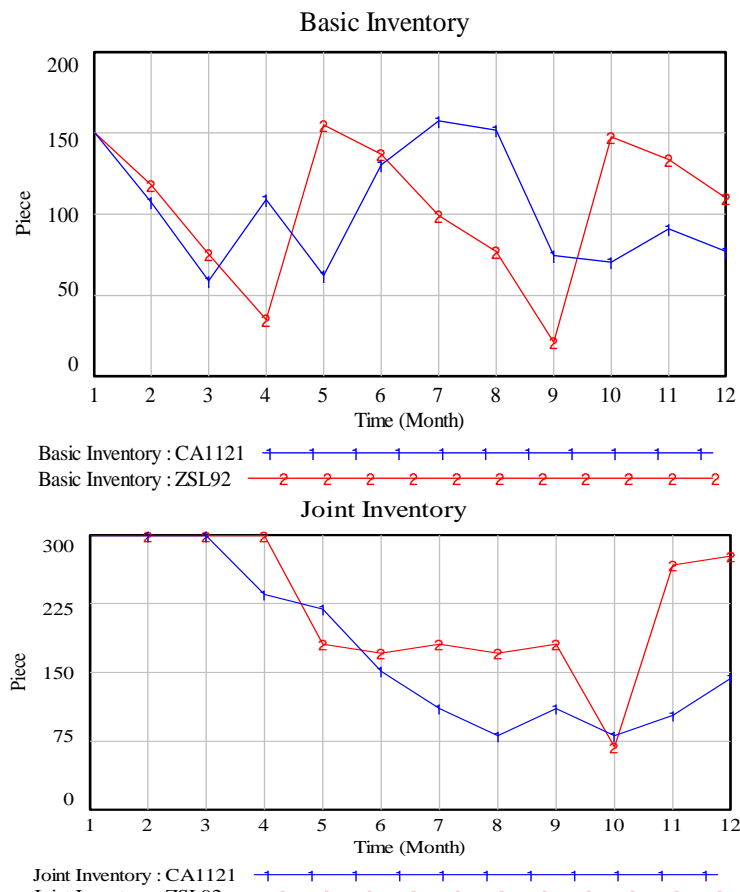

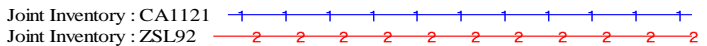

Figure 11. Changes of vehicle equipment inventory
It can be seen from Figure 11 that the average inventory of the ZSL92 bulletproof tires and the CA1121 rearview mirrors were 104.57 and 103.39 , respectively, and the average of joint warehouse was 225.02 and 177.91 , respectively. Due to the changes in inventory demand information, the inventory curve of ZSL92 bulletproof tires is more sensitive, while the CA1121 inventory curve changes gently.

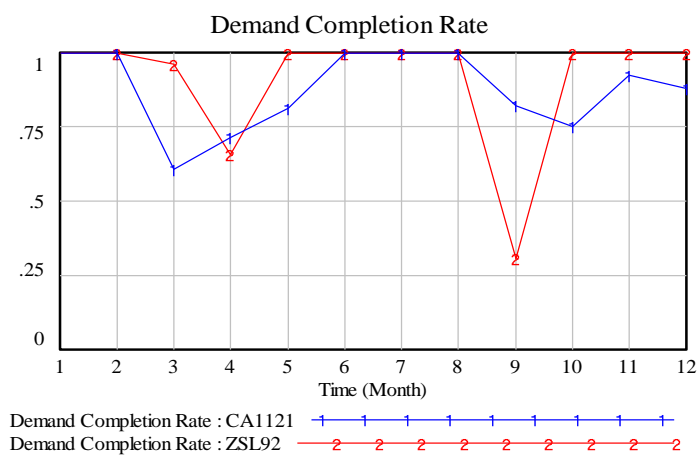

Figure 12. Completion rate for vehicle equipment

It can be seen from Figure 12 that the average annual completion rate of the ZSL92 bulletproof tire and the CA1121 rearview mirror were $90.92 \%$ and $87.57 \%$, respectively. Thus, the priority of PTVES can affect the supply support efficiency of vehicle equipment to a certain extent. In the actual military vehicle equipment management activities, the decision makers can adjust the PTVES priority of the equipment supply support task according to the actual situation, by changing the parameter values of other factors in the model, thereby improving the completion rate of the vehicle equipment.

\section{CONCLUSIONS}

Under the military and civilian joint managed inventory mode of vehicle maintenance equipment integrating production, maintenance, storage and supply, different vehicle equipment supply support tasks were classified to obtain different PTVES values, which can not only avoid the insufficient situation of information processing capability for multiple equipment support tasks, but also adjust the completion rate of the equipment by changing the value of the PTVES table function.

This paper establishes a system dynamics model to simulate and analyse the dynamic operation of the joint inventory system for MTVs' maintenance equipment under different support tasks, which shall provide reference for developing the jointly managed inventory strategy of military vehicle equipment. At present, this paper only studies the MTVs' maintenance equipment support mode under the joint inventory model. In future, further study should be conducted on the emergency classification of supply support system for military vehicle equipment under special military missions (such as combat, military exercises, and disaster relief). This can provide scientific support for top-level design, demonstration and optimization issues in military vehicle maintenance equipment supply support work.

\section{ACKNOWLEDGMENT}

This work is supported by Military Innovative Talents Engineering Fund. 


\section{REFERENCES}

[1] Li YD, Zhang CH, Xie XP. (2017). Study on VMI model of military vehicle equipment. Logistics technology 36(1): 162-164. http://dx.chinadoi.cn/10.3969/j.issn. 1005-152X.2017.01.035

[2] Wang FZ, Wen ZZ, He J. (2015). Optimization and design of combination units of tactical vehicle reserve equipment. Logistics Technology 34(11): 209-212. http://dx.chinadoi.cn/10.3969/j.issn.1005-152X.2015.11. 055

[3] He T, Xie XP. (2016). Study on vehicle material inventory management based on supply chain. Logistics technology 35(2): 117-180. http://dx.chinadoi.cn/10.3969/j.issn.1005152X.2016.02.036

[4] Guo JY, Zhou SQ, Li GL. (2018). Research on the construction of virtual warehouse for military vehicle maintenance equipment. Journal of Ordnance Equipment $\begin{array}{lll}\text { Engineering } & 39(10) \text { : } & 125-130\end{array}$ http://dx.chinadoi.cn/10.11809/bqzbgcxb2018.10.026

[5] Ge HY, Shi Q, Xia W. (2017). Research on simulation of inventory optimization control of equipment maintenance spare parts. Computer Simulation 34(7): 386-390. http://dx.chinadoi.cn/10.3969\%2fj.issn.10069348.2017.07.086

[6] Ma W. (2015). Joint inventory management of auto parts in supply chain environment. China High Tech
Enterprise (31): 72-73

[7] Gao CY. (2013). Study on the economic benefits of joint inventory management. Economy and Management 27(2): 51-56. http://dx.chinadoi.cn/10.3969/j.issn.10033890.2013.02.009

[8] Jiang H, Zhang YC, Yang J. (2013). The cost research of JMI based on supply chain. Logistics Sci-Tech (12): 3335.

[9] Li WH. (2013). Application of combined inventory management method in enterprises in inventory control. Logistics Sci-Tech (12): 75-77.

[10] Zhang ZL. (2013). Joint managed inventory in the supply chain of petroleum enterprises. Logistics Engineering and Management 35(10): 216-218. http://dx.chinadoi.cn/10.3969/j.issn.16744993.2013.10.074

[11] Cai LY, Mao FC, Wang K, Zhou YC. (2014). Research on the US army two-IEVEI maintenance system transformation and inspirations. Journal of Academy of Equipment (5): 40-44. http://dx.chinadoi.cn/10.3783/j.issn.20953828.2014.05.010

[12] Zhong YG, Jia XJ, Qian Y. (2013). System Dynamics. Science Press.

[13] Jia SL. (2013). Vensim software modeling guidelines. School of Economics and Management in Beihang University. 